\title{
Morphological evolution of some migratory Ficedula flycatchers
}

\author{
Diana C. Outlaw ${ }^{1,2}$ \\ ${ }^{1}$ Mississippi State University, Department of Biological Sciences, Mississippi State, MS 39762, USA \\ ${ }^{2}$ E-mail:doutlaw@biology.msstate.edu
}

Key words: ancestral states, phylogeny, migration, morphology

\begin{abstract}
Long-distance migration imposes physiological and morphological selection pressures on birds. The genus Ficedula, a lineage of Old World flycatchers, consists of long- and short-distance migratory species, as well as sedentary species. Members of each of these groups are not reciprocally monophyletic, yet each of the behavioral groups is morphologically distinguishable even when accounting for phylogeny. Long-distance migratory species have more pointed wings than either short-distance migratory or sedentary species, and migratory behaviors and wing pointed-ness are phylogenetically correlated. This suggests that migratory Ficedula species have converged on a migratory phenotype, and that migration may be a selective agent that has shaped the independently-derived migratory Ficedula species in similar ways.
\end{abstract}

\section{Contents}

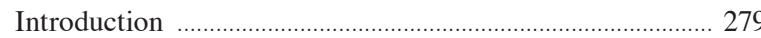

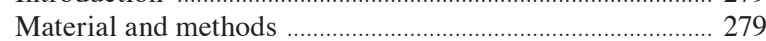

Morphological measurements ........................................... 280

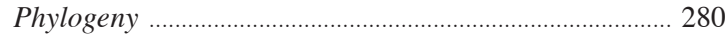

Analyses of morphology ....................................................... 280

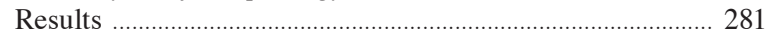

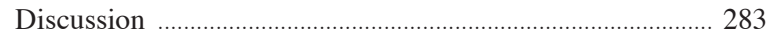

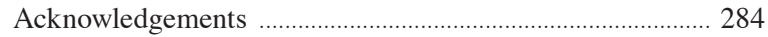

References ………………………………………………....... 284

\section{Introduction}

Many studies over the last century have demonstrated consistent patterns across avian taxa regarding the relationship between wing length and migration distance (Baldwin et al., 2010; Förschler and Bairlein, 2011; Marchetti et al., 1995; reviewed in Mönkkönen, 1995). Generally, long-distance migratory species have longer wings per unit body size than short-distance migratory and sedentary species (Winkler and Leisler, 1992). Closely related bird species are often phenotypically similar, but more distantly related species can converge on a particular morphology if they are subject to similar selection pressures, as has been shown among species in the genus Anthus with regard to both migratory and mating-display behaviors (e.g. Voelker, 2001). Comparative methods (Felsenstein, 1985; Harvey and Nee, 1997) can be used for such questions about convergent evolution, as they are here, to investigate the evolution of migratory behavior and associated phenotypic change (see also Richman and Price, 1992; Richman, 1996).

Studies of the evolution of migration increasingly suggest that long-distance migration has independently evolved multiple times within many avian lineages (Outlaw et al., 2003; Outlaw and Voelker, 2006a, 2008; Boyle and Conway, 2007; Kondo and Omland, 2007; Rheindt et al., 2008; Voelker et al., 2009). Migratory behavior imposes a suite of selection pressures on birds (see Bowlin and Wikelski, 2008) that fly long distances, and this leads to the prediction that migratory birds, both within and across lineages, would have wing shapes, and perhaps overall body shapes, that are optimized for efficient long-distance flight.

Previously, Outlaw and Voelker (2006b) presented a molecular phylogeny of Ficedula, and in a separate paper, reconstructed the evolution of migratory behaviors within the genus (Outlaw and Voelker, 2008). Behavioral diversity within Ficedula flycatchers provides a study system to test hypotheses about convergent morphological evolution among independently-derived long-distance migratory species.

\section{Material and methods}

Ficedula species can be classified according to degrees of migratory behavior (Cramp, 1992; Ali and Ripley, 1996; Coates and Bishop, 1997; Grimmett et al., 1999; Robson, 2000). Each species was assigned to one of the following categories: long-distance migrant, 
Table 1. Ficedula species, behavioral assignments, migration distances, and geographic ranges. LDM: long-distance migratory species; S: sedentary species; SDM: short-distance migratory species. Migration distance is reported in degrees to the nearest $10^{\circ}$. Geographic range includes both breeding and wintering ranges for LDM species. Species are listed as in Fig. 2.

\begin{tabular}{llcl}
\hline Ficedula species & Behavior & Migration distance & Geographic range \\
\hline nigrorufa & S & $0^{\circ}$ & India \\
hodgsonii & SDM & $10^{\circ}$ & South and Southeast Asia \\
dumetoria & S & $0^{\circ}$ & Southeast Asia \\
narcissina & LDM & $45^{\circ}$ & Eastern Palearctic, South and Southeast Asia \\
zanthopygia & LDM & $45^{\circ}$ & Eastern Palearctic, South and Southeast Asia \\
mugimaki & LDM & $40^{\circ}$ & Eastern Palearctic, South and Southeast Asia \\
westermanni & SDM & $0^{\circ}$ & South and Southeast Asia \\
superciliaris & SDM & $15^{\circ}$ & South Asia \\
strophiata & SDM & $0^{\circ}$ & South Asia \\
hyperythra & SDM & $0^{\circ}$ & South and Southeast Asia \\
albicollis & LDM & $60^{\circ}$ & Western Palearctic, Africa \\
hypoleuca & LDM & $60^{\circ}$ & Western Palearctic, Africa \\
parvalalbicilla & LDM & $35^{\circ}$ & Eastern Palearctic, South and Southeast Asia
\end{tabular}

short-distance, altitudinal or partial migrant (collectively hereafter: short-distance migrant), and sedentary (Table 1).

\section{Morphological measurements}

Specimens were selected for measurement from collections at the American Museum of Natural History, the British Museum of Natural History, the Delaware Museum of Natural History, and the Museum of Comparative Zoology (Harvard University). Many Ficedu$l a$ species have poor representation within museums, and this limited the number of species included within this study. For each of 13 Ficedula species (Table 1), between 12 and 16 adult male specimens were measured from one geographic location (within a species) to minimize additional error associated with intraspecific variation. Seven morphological characters were selected including longest primary (usually the eighth) and first secondary lengths, tail length, bill length, width and depth, and tarsus length (Table 2). All were measured with digital calipers to the nearest $0.01 \mathrm{~mm}$ using standard measurement protocols (Proctor and Lynch, 1993).

\section{Phylogeny}

The 13 species measured for morphological characters are a subset of the species forming a monophyletic Ficedula (26 species; Outlaw and Voelker, 2006b). I pruned the topology to include only the 13 species for which morphological data were available, and calcu- lated maximum likelihood branch lengths using the appropriate model of nucleotide substitution $(\mathrm{GTR}+\mathrm{I}+\Gamma$; from Outlaw and Voelker, 2006b). This tree was used in phylogeny-based analyses in this study.

\section{Analyses of morphology}

Body size correction in closely-related birds can be problematic because body weight varies tremendously throughout the annual cycle of birds, often regardless of whether birds migrate or not. Moreover, wing and tail measurements are sometimes not indicative of size (Rising and Somers, 1989). Another problem here is that reliable body weight data are not available for many Ficedula species. In order to deal with these problems, I log-transformed all data prior to analysis, and interpreted ordination results while considering differences in body size between behavioral groups, i.e. most traits load positively on the first factors indicating size differences (Price, 1991).

Analyses of Phenotypes. Discriminant function analyses (DFA) determine whether groups (e.g. LDM, SDM, sedentary) are diagnosable, and were conducted with both species and behavior as the grouping variables. Individual characters were included in analyses of variance (ANOVA); significant ANOVAs were followed by post-hoc tests between all behavioral groups using Dunnett's T3 for non-homogeneity of variance. The first and second principal component scores (from a covariance-based PCA) were included in an ANOVA following the preceding procedure (by behavioral groups; see Voss and Marcus, 1992). All 
Table 2. Log-transformed means (M), standard deviations (SD) by species for each character and wing pointed-ness (WP). Number of specimens measured is listed after each species name. Species are listed as in Fig. 2.

\begin{tabular}{|c|c|c|c|c|c|c|c|c|c|}
\hline Species & & $\begin{array}{l}\text { Longest } \\
\text { primary }\end{array}$ & $\begin{array}{l}\text { First } \\
\text { secondary }\end{array}$ & $\begin{array}{l}\text { Bill } \\
\text { length }\end{array}$ & $\begin{array}{l}\text { Bill } \\
\text { depth }\end{array}$ & $\begin{array}{l}\text { Bill } \\
\text { width }\end{array}$ & $\begin{array}{l}\text { Tail } \\
\text { length }\end{array}$ & $\begin{array}{l}\text { Tarsus } \\
\text { length }\end{array}$ & WP \\
\hline \multirow[t]{2}{*}{ nigrorufa (12) } & $\mathrm{M}$ & 3.639 & 3.253 & 1.965 & 1.204 & 1.421 & 3.893 & 2.941 & 1.47 \\
\hline & $\mathrm{SD}$ & 0.085 & 0.061 & 0.048 & 0.068 & 0.058 & 0.043 & 0.064 & \\
\hline \multirow[t]{2}{*}{ hodgsonii (15) } & $\mathrm{M}$ & 3.891 & 3.362 & 1.826 & 1.106 & 1.180 & 3.988 & 2.721 & 1.70 \\
\hline & $\mathrm{SD}$ & 0.039 & 0.078 & 0.055 & 0.064 & 0.074 & 0.047 & 0.064 & \\
\hline \multirow[t]{2}{*}{ dumetoria (13) } & M & 3.627 & 3.321 & 2.128 & 1.371 & 1.503 & 3.827 & 2.868 & 1.35 \\
\hline & $\mathrm{SD}$ & 0.069 & 0.073 & 0.044 & 0.061 & 0.056 & 0.048 & 0.077 & \\
\hline \multirow{2}{*}{ narcissina (16) } & M & 3.976 & 3.403 & 2.040 & 1.307 & 1.424 & 3.922 & 2.788 & 1.78 \\
\hline & $\mathrm{SD}$ & 0.023 & 0.040 & 0.045 & 0.059 & 0.066 & 0.037 & 0.026 & \\
\hline \multirow{2}{*}{ zanthopygia (16) } & $\mathrm{M}$ & 3.881 & 3.338 & 2.032 & 1.338 & 1.445 & 3.793 & 2.800 & 1.73 \\
\hline & $\mathrm{SD}$ & 0.038 & 0.059 & 0.048 & 0.067 & 0.060 & 0.082 & 0.031 & \\
\hline \multirow[t]{2}{*}{ mugimaki (15) } & $\mathrm{M}$ & 3.904 & 3.365 & 1.849 & 1.087 & 1.233 & 3.928 & 2.732 & 1.72 \\
\hline & $\mathrm{SD}$ & 0.027 & 0.119 & 0.061 & 0.043 & 0.065 & 0.047 & 0.037 & \\
\hline \multirow{2}{*}{ westermanni (15) } & M & 3.621 & 3.193 & 1.874 & 1.071 & 1.284 & 3.704 & 2.730 & 1.54 \\
\hline & $\mathrm{SD}$ & 0.035 & 0.051 & 0.039 & 0.060 & 0.069 & 0.075 & 0.037 & \\
\hline \multirow[t]{2}{*}{ superciliaris (15) } & $\mathrm{M}$ & 3.741 & 3.240 & 1.931 & 1.080 & 1.312 & 3.759 & 2.708 & 1.66 \\
\hline & $\mathrm{SD}$ & 0.024 & 0.059 & 0.044 & 0.053 & 0.072 & 0.068 & 0.034 & \\
\hline \multirow[t]{2}{*}{ strophiata (15) } & $\mathrm{M}$ & 3.852 & 3.379 & 1.863 & 1.107 & 1.242 & 4.070 & 2.922 & 1.61 \\
\hline & $\mathrm{SD}$ & 0.039 & 0.065 & 0.042 & 0.063 & 0.069 & 0.062 & 0.037 & \\
\hline \multirow{2}{*}{ hyperthyra (15) } & M & 3.704 & 3.283 & 1.895 & 1.107 & 1.278 & 3.811 & 2.870 & 1.53 \\
\hline & $\mathrm{SD}$ & 0.053 & 0.081 & 0.073 & 0.058 & 0.060 & 0.093 & 0.032 & \\
\hline \multirow[t]{2}{*}{ albicollis (15) } & $\mathrm{M}$ & 4.068 & 3.435 & 1.899 & 1.183 & 1.386 & 3.897 & 2.817 & 1.89 \\
\hline & $\mathrm{SD}$ & 0.026 & 0.047 & 0.046 & 0.060 & 0.086 & 0.042 & 0.036 & \\
\hline \multirow[t]{2}{*}{ hypoleuca (16) } & M & 4.007 & 3.385 & 1.899 & 1.190 & 1.384 & 3.956 & 2.811 & 1.87 \\
\hline & $\mathrm{SD}$ & 0.035 & 0.112 & 0.047 & 0.078 & 0.066 & 0.039 & 0.058 & \\
\hline \multirow[t]{2}{*}{ parva/albicilla (15) } & $\mathrm{M}$ & 3.865 & 3.301 & 1.932 & 1.112 & 1.303 & 3.925 & 2.822 & 1.76 \\
\hline & $\mathrm{SD}$ & 0.048 & 0.076 & 0.042 & 0.051 & 0.074 & 0.036 & 0.041 & \\
\hline \multirow[t]{2}{*}{ Total (193) } & $\mathrm{M}$ & 3.836 & 3.329 & 1.931 & 1.173 & 1.337 & 3.883 & 2.807 & \\
\hline & $\mathrm{SD}$ & 0.148 & 0.099 & 0.095 & 0.115 & 0.113 & 0.113 & 0.084 & \\
\hline
\end{tabular}

statistical analyses were conducted in SPSS15.

Phylogenetic component of morphological similarity. To assess whether closely-related species are morphologically similar to one another due to shared ancestry, I calculated morphological Euclidean and uncorrected genetic distances. I then performed a onetailed Mantel test on these two dissimilarity matrices with 100,000 permutations (XLSTAT 2008).

Phylogenetic relationship between behavior and morphology. Maximum likelihood based analyses of character evolution provide a way to evaluate whether characters are phylogenetically correlated (Discrete Program; Pagel, 1999) using likelihood ratio tests. I included migratory behavior, coded as migratory or non-migratory ( 1,0 , respectively), and three characters (separately): Principal Component 1, coded as above or below the averaged $\mathrm{PC} 1$ value $(-0.03)$ for all species (1, 0, respectively); Principal Component 2, coded as above or below the averaged PC2 value (0.0095) for all species $(1,0$, respectively); and a wing-pointed-ness index (longest primary length/first secondary length, hereafter referred to as WP), coded as above or below the mean index value (1.14) for all species $(1,0$, respectively). I coded characters in this way because these analyses require discrete, binary traits. I then conducted (MCMC) simulations to assign probabilities to character evolution likelihood ratio tests (see Outlaw and Voelker, 2006a). Finally, I used parsimony to reconstruct the evolution of WP (Mesquite Program; Maddison and Maddison, 2010).

\section{Results}

Overall, jackknifed DFA (Fig. 1a) was able to correctly classify $84 \%$ of individuals to species. In these analyses, ninth primary length was the most important discriminating character, followed by tarsus length and tail length. With regard to behavioral groups, jackknifed DFA correctly classified $87 \%$ of individuals to 

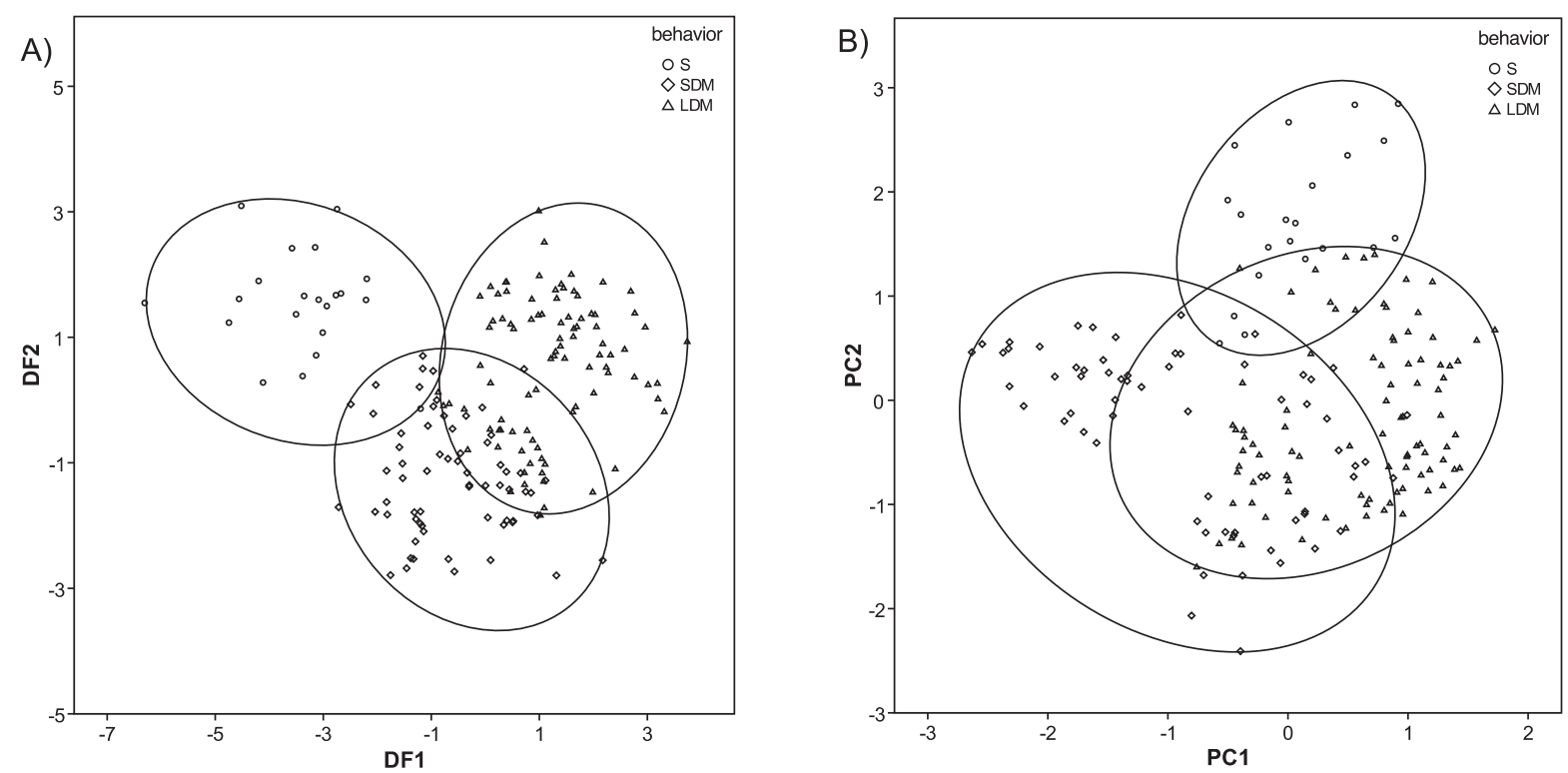

Fig. 1. Scatterplots of Discriminant Function (A) and Principal Component (B) scores for behavioral groups. S: sedentary, SDM: shortdistance migratory, LDM: long-distance migratory.

group; incorrectly classified individuals fell between the SDM and LDM groups, but not between either of the latter and the S group; in these analyses, longest primary length was overwhelmingly the most important discriminating character.

ANOVAs on individual characters were significant across behavioral groups ( $p<0.001$ in all cases). Posthoc tests revealed that behavioral groups were different in longest primary, and the three bill measurements ( $p<0.01$ in all cases). For first secondary and tail lengths, sedentary and LDM species are significantly different $(p<0.01)$, although sedentary and SDM species are not. In tarsus length, SDM and LDM groups are not significantly different, although sedentary species are different from both migrant groups $(p<0.01$ in both cases).
In PCA (Fig. 1b), high positive loadings of wing and tail characters on the first component suggest that $37 \%$ of the variance between individuals is associated with differences in these characters (Table 3). The second component, $33 \%$ of the variance, has high positive loadings for the three bill characters. An ANOVA on Principal Component one (by behavior) indicated a linear increase from sedentary to short-distance to migratory species, which primarily reflects increasing size while Principal Component two, which suggests that wing and tail lengths are inversely related to bill traits, indicates the reverse trend (results not shown); the two components are significantly different $(p<$ 0.001, overall and post-hoc) between groups.

A Mantel test of morphological and genetic distances suggests that the matrices are positively correlated

\begin{tabular}{lcccc}
\hline & \multicolumn{2}{l}{ Principal components } & \multicolumn{2}{l}{ Character correlations } \\
\hline & 1 & 2 & 1 & 2 \\
\hline Longest primary & 0.939 & 0.032 & 0.697 & -0.562 \\
First secondary & 0.781 & 0.214 & 0.719 & -0.341 \\
Bill length & -0.169 & 0.869 & 0.367 & 0.780 \\
Bill depth & 0.127 & 0.896 & 0.611 & 0.616 \\
Bill width & -0.085 & 0.876 & 0.410 & 0.729 \\
Tail length & 0.727 & -0.161 & 0.539 & -0.553 \\
Tarsus length & -0.019 & 0.339 & 0.298 & 0.345 \\
Variance explained & $37.65 \%$ & $33.41 \%$ & & \\
\hline
\end{tabular}

Table 3. Rescaled principal component loadings for each character, correlations of each component with each character, and variance explained by each component. Principal components are based on covariance. All correlations are significant $(\mathrm{p}<0.01)$. 


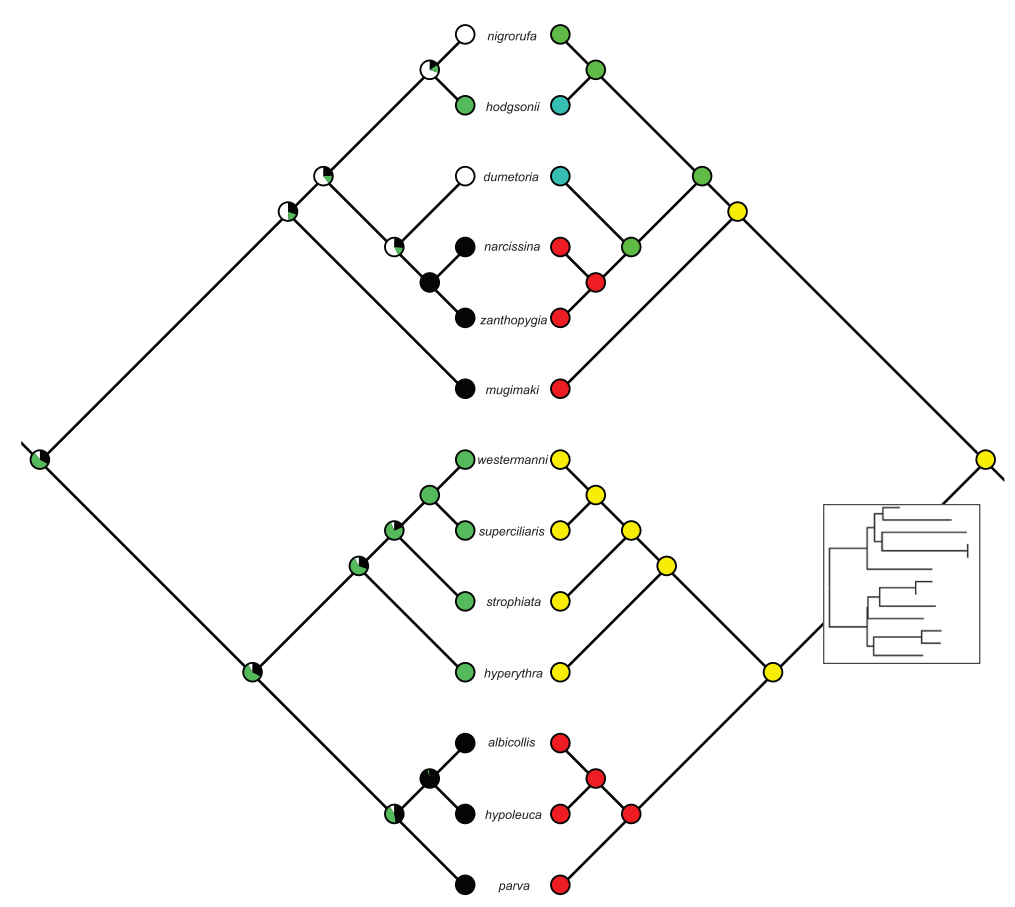

Fig. 2. Molecular phylogeny of Ficedula species included in this study (data from Outlaw and Voelker, 2006b). Circles at tips reflect character states of extant taxa and pie charts at nodes reflect ancestral character states. Left, migratory behaviors: white $=\mathrm{S}$, black $=\mathrm{LDM}$, green $=$ SDM. Right, Wing pointed-ness from smallest to largest: green, blue, yellow, red. Note $F$. parva refers to $F$. parva and $F$. albicilla. Inset: phylogram with species ordered as in larger figure.

and that $36.5 \%$ of morphological variation can be explained by phylogenetic relatedness $(p<0.001)$.

Likelihood ratio tests of migratory behavior and morphology (above/below averaged PC1 mean; Table 3 ) as independent or dependent (phylogenetic correlation) indicate a significant difference: $\Delta \log$-likelihood $=3.61, p<0.001$ (simulation: 100 iterations). Likewise, there is a significant phylogenetic correlation for behavior and WP: $\Delta \log$-likelihood $=5.47, p<0.001(\mathrm{sim}$ ulation: 100 iterations), but not for behavior and PC2: $\Delta \log$-likelihood $=0.69$.

\section{Discussion}

Long-distance migratory species within the genus Ficedula exhibit morphological similarities, which suggest that migratory behaviors produce an "optimal" migratory phenotype. Although a proportion of variation among Ficedula species can be attributed to phylogenetic relatedness $(36.5 \%)$, the results here suggest that sedentary, SDM and LDM Ficedula species form distinct morphological groups. One factor distinguishing these groups appears to be size; LDM species are larger than SDM, and SDM species are larger than sedentary species. However, WP accounts for size (being a ratio) and it is clear that LDM species have more pointed wings than SDM species, and SDM species more than sedentary species. The two species with the lowest
WP (nigrorufa and dumetoria) have the most restricted geographic ranges of species included here. Moreover, because some species within each behavioral group are independently-derived, part of the distinction between groups is due to non-phylogenetic causes, i.e. selection. The wing shape of LDM species can be construed as a reflection of their adaptation to increased flight efficiency. At the same time, SDM species primarily represent a middle-ground between LDM and sedentary species. Bill shape is highly variable between species, but so little is known about the diets and foraging habits of many Southeast Asian species, that I cannot speculate about selection on bill characters.

This study also shows that LDM behavior can predict morphology. When ancestral states shift from sedentary to migratory, the descendents are more likely to exhibit a particular phenotype (i.e., are larger with more pointed wings; Fig. 2). The results are not unexpected because morphological differences have been and are consistently noted between sedentary and migratory lineages (at multiple taxonomic levels; see also Dawideit et al., 2008), and a recent study highlights the biomechanical underpinnings to explain those differences (Bowlin and Wikelski, 2008).

A notable result from this study is that LDM Ficedula species, in very different breeding and wintering habitats, exhibit morphological similarities that have evolved repeatedly. This study suggests that convergent morphological evolution occurs in response to 
the physical demands of migratory behaviors, and provides a framework for more detailed analyses within other lineages of birds.

\section{Acknowledgements}

This research was conducted in partial fulfillment of the requirements for a doctor of philosophy degree. Gary Voelker, Scott Franklin, Stephen Schoech, Matthew Parris, and two anonymous reviewers provided valuable insight, comments and criticisms. This research could not have been completed without the assistance and support of Robert Outlaw, to whom the author is extremely grateful. This research was funded by a NSF Doctoral Dissertation Improvement Grant DEB 0508452, a Society of Systematic Biologists' Graduate Student Research Award, an American Ornithologists' Union Research Grant, an American Museum of Natural History Collections Study Grant, a Delaware Museum of Natural History Collections Study Scholarship, a Donovan Travel Enrichment Grant, and NSF DEB 0613668 to Gary Voelker and R.C.K. Bowie. Special thanks to the curators and collections managers for allowing me access to museums, and to Mark Adams for sending specimens from the British Museum of Natural History.

\section{References}

Ali S, Ripley SD. 1996. Handbook of the birds of India and Pakistan, v. 7. New Delhi: Oxford University Press.

Baldwin MH, Winkler H, Organ CL, Helm B. 2010. Wing pointedness associated with migratory distance in common garden and comparative studies of stonechats (Saxicola torquata). Journal of Evolutionary Biology 23: 1050-1063.

Bowlin MS, Wikelski M. 2008. Pointed wings, low wingloading and calm air reduce migratory flight costs in songbirds. PLOS ONE 3: e2154.

Boyle WA, Conway CJ. 2007. Why migrate? A test of the evolutionary precursor hypothesis. American Naturalist 169: 344-359.

Coates BJ, Bishop KD, Gardner D. 1997. A guide to the birds of Wallacea. Alderley: Dove Publications.

Cramp S. 1992. The birds of the western Palearctic, v. VII. Oxford: Oxford University Press.

Dawideit BA, Phillimore AB, Laube I, Leisler B, Böhning-Gaese K. 2008. Ecomorphological predictors of natal dispersal distances in birds. Journal of Animal Ecology 78: 388-395.

Felsenstein J. 1985. Phylogenies and the comparative method. American Naturalist 125: 1-15.

Förschler MI, Bairlein F. 2011. Morphological shifts of the external flight apparatus across the range of a passerine (northern wheatear) with diverging migratory behavior. PLoS One 6: e18732.

Grimmett C, Inskipp C, Inskipp T. 1998. A guide to the birds of India. Princeton: Princeton University Press.

Harvey PH, Pagel MD. 1991. The comparative method in evolutionary biology. Oxford: Oxford University Press.

Kondo B, Omland KE. 2007. Ancestral state reconstruction of migration: multistate analysis reveals rapid changes in New
World orioles. Auk 124: 410-419.

Maddison WP, Maddison DR. 2001. Mesquite: a modular system for evolutionary analysis, v. 0.98. http://mesquiteproject.org

Marchetti K, Price T, Richman A. 1995. Correlates of wing morphology with foraging behavior and migration distance in the genus Phylloscopus. Journal of Avian Biology 26: 177-181.

Mönkkönen M. 1995. Do migratory birds have more pointed wings? A comparative study. Evolutionary Ecology 9: 520528.

Outlaw DC, Voelker G, Mila B, Girman DJ. 2003. The evolution of migration in, and historical biogeography of the Catharus thrushes: A molecular phylogenetic approach. Auk 120: 299-310.

Outlaw DC, Voelker G. 2006a. Phylogenetic tests of hypotheses for the evolution of avian migration: A case study using the Motacillidae. Auk 123: 455-466.

Outlaw DC, Voelker G. 2006b. Systematics of Ficedula flycatchers (muscicapidae): a molecular reassessment of a taxonomic enigma. Molecular Phylogenetics and Evolution 41: 118-126.

Outlaw DC, Voelker G. 2008. Pliocene climatic change in insular Southeast Asia as an engine of diversification in Ficedula flycatchers. Journal of Biogeography 35: 739-752.

Pagel M. 1999. The maximum likelihood approach to reconstructing ancestral character states of discrete characters on phylogenies. Systematic Biology 48: 612-622.

Price TD. 1991. Morphology and ecology of breeding warblers in Kashmir, India. Journal of Animal Ecology 60: 643-664.

Proctor NS, Lynch PJ. 1993. Manual of Ornithology. New Haven: Yale University Press.

Rheindt FE, Christidis L, Norman JA. 2008. Habitat shifts in the evolutionary history of a Neotropical flycatcher lineage from forest and open landscapes. BMC Evolutionary Biology: 193.

Richman AD, Price T. 1992. Evolution of ecological differences in the old world leaf warblers. Nature 355: 817-821.

Richman AD. 1996. Ecological divergence and community structure in the Old World leaf warblers (genus Phylloscopus). Evolution 50: 2461-2470.

Rising JD, Somers KM. 1989. The measurement of overall body size in birds. Auk 106: 666-674.

Robson C. 2000. A guide to the birds of Southeast Asia. Princeton: Princeton University Press.

Voelker G. 2001. Morphological correlates of migratory distance and flight display in the avian genus Anthus. Biological Journal of the Linnean Society 73: 425-435.

Voelker G, Rohwer S, Outlaw DC, Bowie RKC. 2009. Repeated trans-Atlantic dispersal catalysed a global songbird radiation. Global Ecology and Biogeography 18: 41-49.

Voss RS, Marcus LF. 1992. Morphological evolution in muroid rodents ii. craniometric factor divergence in seven neotropical genera, with experimental results from Zygodontomys. Evolution 46: 1918-1934.

Winkler H, Leisler B. 1992. On the ecomorphology of migrants. Ibis 134: 21-28 (Supplement).

Received: 22 June 2011

Revised and accepted: 16 September 2011

Published online: 6 December 2011

Editor: V. Nijman 